\title{
El espacio simbólico en el antiguo convento de la Magdalena de Antequera (Málaga)
}

The symbolic space in the former convent of the Magdalena de Antequera

(Málaga)

José Antonio Vázquez Sánchez1

${ }^{1}$ Departamento de Historia del Arte, Universidad de Málaga, España (javazsan@gmail.com)

Recibido el 8 de Enero de 2017; revisado el 15 de abril de 2017; aceptado el 3 de mayo de 2017; publicado el 1 de julio de 2017

RESUMEN: El antiguo convento de santa María Magdalena de Antequera (Málaga), perteneciente a la Orden de los Hermanos menores de la estricta observancia o franciscanos descalzos alcantarinos, constituye uno de los mejores ejemplos de la religiosidad anacoreta del barroco andaluz, profusamente decorado con pinturas al temple, configurando un espacio simbólico conventual basado en las doctrinas del fundador de la Orden, san Pedro de Alcántara y reflejadas en su libro Tratado de Oración y Meditación (1587). Esta obra constituye una de las joyas de la mística española, cuya función era ayudar a cualquier persona que quisiera conseguir la unión del alma con Dios mediante la purificación de sus vicios y sus pecados, con unas reglas estrictas de pobreza absoluta, descalcez, retiro para la oración y abandono total en manos de la Providencia Divina y el ministerio de la predicación.

Palabras claves: Convento de la Magdalena, Antequera, San Pedro de Alcántara, Barroco, Andalucía, Tratado de Oración y Meditación, Misticismo.

\begin{abstract}
The old convent of Santa María Magdalena de Antequera (Malaga), which belongs to the Order of Friars Minor of strict observance or alcantarinos barefoot Franciscan, was built between 1690 and 1708 and constitutes one of the best examples of the anchorite religiosity of the andalusian baroque, profusely decorated with tempera paintings, configuring a symbolic convent space based on the doctrines of the founder of the Order, San Pedro de Alcántara, reflected in his book Treatise on Prayer and Meditation (1587). This work constitutes one of the jewels of the Spanish mysticism, whose function was to help anyone who would like to achieve the union of the soul with God by purifying their vices and their sins, with strict rules of absolute poverty, barefootedness, retreat for prayer and total abandonment into the hands of Divine Providence and the ministry of preaching.
\end{abstract}

KEYWORDS: Convent of the Magdalena, Antequera, San Pedro de Alcántara, Baroque, Andalusia, Treaty of Prayer and Meditation, Mysticism 


\begin{abstract}
“Antequera constituye una de las ciudades más importantes del barroco andaluz, con una gran riqueza cultural y económica, que aspiraba a condensar el paradigma de la ciudad tridentina ideal: síntesis de Jerusalén y Roma, y como en aquellas ciudades, también existían siete colinas que la rodeaban, un monte Gólgota o Calvario (el cerro de la Vera Cruz) y un "desierto", el retiro anacoreta (el convento de la Magdalena)" (Parejo, 2002: 14).
\end{abstract}

El retiro anacoreta, también llamado Convento de los Franciscanos Menores Alcantarinos de la Magdalena, constituye uno de los elementos artísticos más importantes de Antequera, representando unos valores espirituales y culturales que se encuentran enraizados en la sociedad. La fundación de este convento se realiza en el año 1686, pero ya existía este mismo lugar un eremitorio o lucus eremus, erigido por un rico comerciante de Antequera, don Alfonso Álvarez de Tejada, en el año 1570, también llamado de la Magdalena.

El establecimiento de la Orden de los Descalzos alcantarina en el lugar se produce gracias al importante apoyo del obispo de Málaga, fray Alonso de Santo Tomás, personaje relevante del siglo XVII español, importante teólogo, filósofo y orador, pese a la oposición de los conventos de la ciudad de Antequera y del propio Cabildo. Se construyó una nueva fábrica, que es la que se aún se conserva, en el lugar donde anteriormente existía una pequeña capilla y algunas estancias, entre los años 1690y 1708 .

En el año 1820, como consecuencia del decreto de desamortización eclesiástica, los monjes del lugar fueron expulsados, los bienes del culto se aportaron a la iglesia de san Miguel en Antequera y el convento fue declarado "bien nacional" para su posterior venta por parte del Estado. A partir de este momento llega un periodo de decadencia, reutilizándose el propio convento como cortijo, al ser comprado el edificio y las tierras colindantes por una familia procedente de la burguesía antequerana, ubicándose en el mismo una almazara de aceite, molino de harina, bodega de vino, granero, cuadras para animales y, en las antiguas celdas de los monjes, habitaciones para el encargado y trabajadores del propio cortijo.

Pero, a principios del presente siglo, la sociedad Antequera Golf reconvierte el cortijo agrícola en un hotel de lujo, realizando una importante labor de rehabilitación del edifico y restauración de las pinturas que se encuentran en el mismo, aunando una labor de tipo económico y la recuperación de un patrimonio relevante y único. 


\section{Breve historia de la Orden de los Franciscanos Menores de san Pedro de}

\section{Alcántara}

A principios del siglo XIV se inició en diferentes puntos de Europa el intento de formar grupos de frailes franciscanos que querían seguir de un modo literal las reglas de San Francisco de Asís, los cuales aspiraban a realizar una vida eremítica con los principios más estrictos de austeridad, silencio, pobreza y penitencia.

Estos llegaron a España de la mano de fray Pedro de Villacreces y fray Gonzalo Mariño, creando eremitorios $\mathrm{u}$ oratorios rurales a principios del siglo XV y constituyendo así el germen de las reformas franciscanas que tendrían su continuidad durante la Edad Moderna. Después de diversas vicisitudes, fue San Pedro de Alcántara, nacido en el año 1499 en Alcántara (Badajoz), el que le dio el impulso definitivo a la Orden de los Hermanos menores descalzos de la estricta observancia (Ordo Fratrum Minorum Discalceatorum) o simplemente, franciscanos descalzos1. En 1538 fue elegido Padre Provincial de la Provincia de San Gabriel de los Frailes Menores Descalzos, pero abandonó este puesto y se fue a hacer una vida de ermitaño en las montañas de Arrábida (Portugal) en el año 1542. Pronto se le unen otros frailes y crean pequeñas comunidades que se convirtieron en 1560 en la provincia de Arrábida.

En el año 1555 y 1557, san Pedro de Alcántara construye un pequeño convento en El Palancar, en Cáceres, en una modesta casa de campo que le fue donada por don Francisco de Chávez y su esposa. En el año 1559 fue nombrado comisario general de los conventos reformados de España, erigiéndose en Custodia bajo el título de San José. El papa Pablo IV aprobó la creación de esta nueva Custodia en la Bula Cum a nobis para todos los conventos reformados de España; es lo que ha venido a llamarse como la "Observancia de los llamados franciscanos alcantarinos", con unas reglas de austeridad extrema: prohibición del calzado, consumo de carne y las bibliotecas.

Fue el apoyo y director espiritual de santa Teresa de Ávila, a la que aconsejó el santo franciscano para realizar la reforma del Carmelo. Además, fue solicitado por el emperador Carlos V para ser su confesor y consejero espiritual, cargo que no aceptó.

\footnotetext{
${ }^{1}$ Era hijo de nobles y estudió en la Universidad de Salamanca Derecho civil y canónico, dejando sus estudios a los dieciséis años y tomando el hábito franciscano en el año 1515, ingresando en el convento de franciscano de los Majarretes, junto a Valencia de Alcántara (Badajoz).
} 
Falleció en el año 1562, siendo beatificado en el año 1622 por Gregorio XV, que le llamó Doctor y Maestro iluminado de Teología Mística y canonizado por Clemente IX en el 1669. Asceta y maestro de penitencia, san Pedro de Alcántara cultivó y alimentó la religiosidad de la gente sencilla. En su vida solo escribió un libro, el cual se considera una de las joyas de la mística española, publicado en 1587 y titulado Tratado de la Oración y Meditación, con la finalidad de enseñar a orar y meditar a los hermanos de la comunidad, por tanto, libro básico para todo aquél que quisiera entrar en la comunidad alcantarina.

\section{Correlación del Tratado de la Oración y Meditación con el espacio conventual}

Este Tratado tiene una gran importancia a la hora de comprender el desarrollo del programa iconográfico del convento de la Magdalena y su relación simbólica con el espacio conventual. Dentro de él encontramos un conjunto de pinturas murales realizadas al temple en grisalla, de trazos negros y medias tintas en grises, cuyos autores son anónimos. Todo ello crea un efecto similar a la yesería barroca, elemento característico de la tradición de la arquitectura andaluza del siglo XVII y XVIII, de procedencia italiana; además, la elección de esta técnica se debe a que es la más económica de las existentes y se ajusta a los principios de austeridad de la propia Orden franciscana de san Pedro de Alcántara. A su vez, esta técnica pictórica tiene un gran valor simbólico, ya que el uso de la grisalla está pensado para dar y provocar la sensación de negatividad, asociado a la muerte, a la desesperación y al dolor y en este espacio tiene su significado iconográfico, representando la mortificación, el desaliento, la desesperación, la angustia y el sufrimiento.

El Tratado se dividió en capítulos, cada uno de ellos asignados a un día de la semana, siendo el lunes, quizás, la clave hermenéutica del Tratado, el cual dice: "Este día podrás entender en la memoria de los pecados, y en el conocimiento de ti mismo, para que en lo uno veas cuantos males tienes y en lo otro cómo ningún bien tienes que no sea de Dios” (Alcántara, 2012: 14). Por lo tanto, plantea dos ideas básicas: reconocer los pecados y las acciones negativas del hombre y recordar que el bien descansa en Dios, por ello tenemos que seguir la vía espiritual y el abandono de la vía material.

Por los datos que aportamos, consideramos que el espacio simbólico del convento se distribuye según el plano adjunto [1] en zaguán, claustro bajo, sacristía, iglesia, refectorio, escalera de ascensión al claustro alto y los dormitorios (Camacho, 2008: 124). 


\section{1.- El Zaguán}

Se trata del primer espacio por donde entra el novicio al convento, marcado en el plano con el número 1, un lugar de gran valor simbólico que recuerda y reconoce los pecados anteriores, "Para esto, debes primero pensar en la muchedumbre de los pecados de vida pasada. Especialmente en aquellos que hiciste en el tiempo en el tiempo que menos conocías a Dios" (Alcántara, 2012: 15). Porque han sido muchos los pecados, tanto de pensamiento, palabras y obras, expresando la voluntad de dejar la vida de pecado para buscar la vía mística y el bien de Dios.

Esta idea se representa por medio de inscripciones de tipo poética, que tiene una gran capacidad nemotécnica, realizadas con ayuda de plantillas, con una grafía menuda y preciosista, de las cuales se conservan en este espacio cuatro cartelas, dos de ellas restauradas y que reproducimos a continuación:

"Es tanto lo que ofendí,

Que he llegado a confiar,

Que me habéis de perdonar,

Porque no hay que hacer de mí.

Ya solo hay clemencia aquí

$\mathrm{Y}$ es en vuestro solio eterno,

El más seguido gobierno,

Que según es mi malicia,

O no habéis que hacer justicia

O habéis de hacer otro infierno".

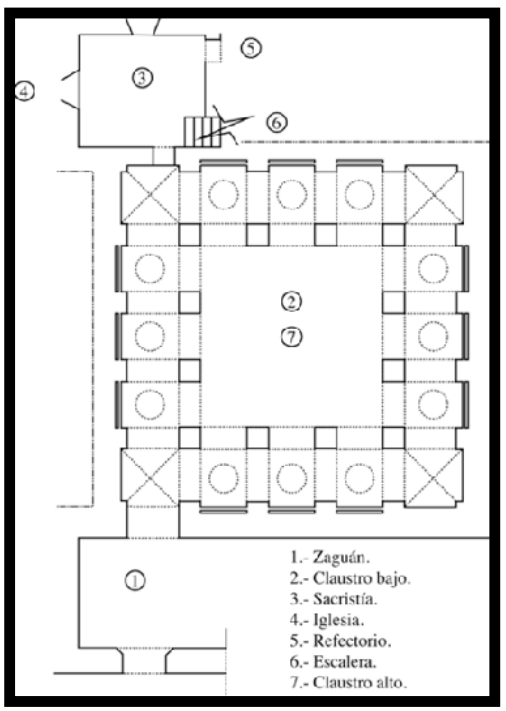

[Fig. 1] Plano general del convento. 
La primera actitud del novicio en la entrada a este lugar de meditación es la desilusión por el mundo terrenal y el reconocimiento de todos los pecados cometidos, ya que la condición del hombre es una disposición a pecar por "obra o por palabra o por pensamiento" (Alcántara, 2012: 15). La segunda cartela dice lo siguiente:

\footnotetext{
"Si hallé gracia en tus ojos, y me quieres,

El resto de mis años podre $\mathrm{d}[$ arte]

Que no quiero otro bien, ni otro[s quereres]

Si ver, que aun que tan vil puedo gozarte,

Enséñame mi Dios por donde fueres,

Que es un loco el que deja de buscarte

Pues pudiendo gozar bienes eternos

Se quiere sepultar en los infiernos".
}

En este segundo poema le pide a Dios que le enseñe el camino para conseguir los bienes eternos; para ello tiene que pasar por un arco triunfal, la entrada a un lugar nuevo donde se produce el renacer de una nueva vida llena de riquezas espirituales.

\section{2.- Arco de entrada al claustro}

El siguiente espacio es relativo a la representación de un arco triunfal, donde se encuentra pintado el escudo de la Orden y unas golondrinas en la parte superior que revolotean alrededor del mismo, junto a unos ramilletes de frutas y flores representando la primavera: el renacer de una nueva vida. El monje, al pasar este arco, deja atrás la materialidad del mundo terrenal, el pecado y los vicios.

En los dos lados del intradós de este arco se encuentran otros dos poemas; el de la izquierda recuerda El Gran Teatro de Mundo, de Calderón de la Barca, donde dice que la vida en la tierra es un teatro y el Autor -Dios- de la comedia es el que marca el papel que representa cada uno en esta vida: todo es vano y efímero en la vida terrenal; lo verdaderamente importante es la vida que existe después de esta y para ello tiene que seguir unas de las normas del fundador, el abandono total del monje en manos del Creador.

\footnotetext{
"No dudes, es Comedia nuestra vida,

Y teatro de farsa el mundo todo,

Y que somos farsantes del tal modo,
} 
Que se haga el papel según Dios Pida;

Si fuere corto, o largo, no es estorbo,

Ni el que sea de uno, ó otro Personaje,

Ni que mude de traje, ó de lenguaje,

Como de enfermo, sano, recto, o corvo,

O de rico, de pobre, o de un esclavo;

Procura no faltar, ni en una jota,

Ya su ejecución pronta, solo apeles,

Que saldrás bien con tu papel de cabo;

Pues que a $\mathrm{t}$ los dichos, y papeles,

La representación, o mucha o poca

Solo el Autor de la comedia toca".

En el intradós derecho figuran otros versos de estilo propagandístico, en los que se informa al novicio de la grandeza de la Orden franciscana, de la que él va a ser partícipe, orden con doce mil conventos repartidos por todo el mundo, mil mártires, cuatrocientos santos, seiscientos beatos y cuatro papas. Todos ellos han conseguido llegar a Dios siguiendo el ejemplo del fundador de la Orden Franciscana, san Francisco de Asís, por lo tanto, es el correcto camino que tiene que seguir el monje en la tierra, con una vida dedicada a la oración y meditación:

"En Provincias doscientas, y sesenta

Al Orbe abrazan doce mil Conventos,

Siete en Jerusalén, y entre sangrientos

Turcos, y sarracenos mas de treinta.

Mártires sobre mil, y cuatrocientos,

Y santos cuarenta ya Canonizados,

Sin seiscientos, que están Beatificados

Gozando dela gloria los asientos,

Cuatro Papas, sesenta Cardenales;

Inquisidores mil, Reyes cuarenta,

Mitras, Cátedras, Plumas infinitas;

Del gran Francisco son grandezas tales,

Y la mayor de cuantas hay escritas

Es, ver, que un Pobre sin ápice de renta

Todo lo mantiene, lo cuida y lo sustenta". 


\section{3.- El claustro bajo}

Marcado en el plano con el número 2, se trata del lugar de meditación que ayuda a superar el pecado evocando las excelencias de los padres franciscanos y, en especial, seguir el mismo camino que María Magdalena, una gran pecadora pero que, con arrepentimiento, penitencia y oración llegó a conseguir el Paraíso.

Una vez que se entra en el espacio del claustro, se tiene que "meditar sobre las penas del infierno como medio para confirmar el temor a Dios y el aborrecimiento del pecado, y se tiene que realizar debajo de algunas figuras y semejanzas corporales” (Alcántara, 2012: 26). Con el propósito de recordar lo que los santos nos enseñaron, se representan, en las bóvedas vaídas, los santos capitales de la Orden franciscana enmarcados en un medallón central, alternando un santo masculino con otro femenino. Cada una de estas imágenes está rodeada de cuatro cartelas con frases latinas, haciendo mención a las cualidades de cada una de los personajes representados. Los doctores franciscanos encarnados son: Duns Scotto, santa Clara, san Buenaventura, santa Isabel de Hungría, san Luis obispo de Tolosa, santa Coleta, san Bernardino de Siena, santa Margarita de Cortona, san Diego de Alcalá, santa Rosa de Viterbo, san Pascual Bailón, en total, once santos que acompañan a la representación de la Virgen María, como intercesora para llegar a Dios.

Las bóvedas de arista siguen el mismo esquema ornamental, aunque sustituyéndose el medallón central por una macolla vegetal rodeada por cuatro cartelas con frases latinas. En la primera bóveda, pasado el arco que une el zaguán con el claustro, se representa de una forma alusiva a Eva, como origen de la muerte corporal. En las siguientes bóvedas se hace alusión a san Francisco como Signifer Christus, a san Francisco o san Antonio de Padua y la última bóveda a san Pedro de Alcántara.

Estas bóvedas están completamente cubiertas por roleos, tornapuntas y acantos en los que aparecen representados niños desnudos cabalgando sobre fogosos caballos y pájaros exóticos, o bien tocando trompetas a modo de la Fama, comunicando a los cuatro puntos cardinales las excelencias y virtudes de los doctores y santos franciscanos representados.

En los tímpanos de cada una de las bóvedas vaídas se representan doce escenas de la vida de María Magdalena, desde su presentación como hija de nobles hasta su muerte, pasando como exemplum expuesto por san Pedro de Alcántara en su Tratado, cuando dice: "Derríbate con aquella 
pública pecadora a los pies del Salvador” (Alcántara, 2012: 17). También dice en otro capítulo refiriéndose a la alegría después de tener una vida piadosa y su reencuentro con Jesús (Alcántara, 2012: $55)$ :

\begin{abstract}
"Considera la alegría de aquellas santas Marías, y especialmente de aquella que perseveraba llorando par del sepulcro cuando viese el amado de su ánima, y se derribase a sus pies y hallase resucitado y vivo al que buscaba y deseaba ver siquiera muerto; y mira bien que, después de la Madre, a aquella primera apareció que más amó, más perseveró, más lloró y más solitamente le buscó, para que así tengas por cierto que hallarás a Dios, si con estas mismas lágrimas y diligencias lo buscares".
\end{abstract}

La representación de las escenas de la vida de santa María Magdalena tiene sus fuentes literarias en el libro de Juan Estaban de la Torre, titulado La Pecadora santa. Vida de santa María Magdalena. Historia Panegírica, política y moral. Dedicada al Antiquissimo, nobilísimo y fidelissimo Reyno de Aragón, publicado en el año 1688. Igualmente, las fuentes icónicas de la representación figurativa tienen su correspondencia con las estampas del prestigioso taller de la familia Sadeler, importantes artistas, grabadores, impresores y editores flamencos de finales del siglo XVI.

Junto a la representación escenográfica de la vida de María Magdalena se encuentran, en los fajones de cada arco, unas cartelas de rasgueos con poemas en su interior escritos por el místico franciscano Antonio Panes (1621-1676), en su libro titulado Escala Mística y estímulo de amor divino (1643). Son de una gran belleza y sirven de apoyo a la oración y meditación, constituyendo una clave fundamental para seguir la doctrina de san Pedro de Alcántara. En total son visibles de una forma parcial o total trece poemas de este autor en este espacio. Entre estos poemas reproducimos uno de ellos, titulado Afectos de Contriccion (Panes, 1743: 190), el cual se encuentra ubicado en la escena que representa la conversión de María Magdalena.

\footnotetext{
“O, Señor, quien viniera tan contrito,

Que de dolor, y puro amor muriera!

Confiesso que fue enorme mi delito,

Que fue mi culpa abominable, y fiera,

Pues antepuse a un Dios un apetito,

La falsa, à la hermosura verdadera.

Vuestra piedad inmensa me reciba:

Pues que gustáis; que me convierta; y viva"
} 


\section{4.- La sacristía}

El siguiente espacio simbólico del convento está marcado en el plano con el número 3. Está dedicado a la Virgen María, situado en un lugar de salida del claustro bajo y de acceso a la iglesia. Seguidamente encontramos el refectorio y unas escaleras de acceso al claustro alto y los dormitorios. San Pedro de Alcántara dice en su tratado: “;Oh María, María, María Virgen Santísima, Madre de Dios, Reina del cielo, Señora del mundo, Sagrario del Espíritu Santo, Rosa de paciencia, Paraíso de deleites, Espejo de Castidad, Dechado de inocencia! Ruega por este desterrado y peregrino, y parte con él de las sobras de tu abundantísima caridad" (Alcántara, 2012: 67). El desarrollo iconográfico de este texto se realiza con la representación de la Virgen María como Inmaculada Concepción, la representación simbólica del tabernáculo viviente de Cristo y dos pelícanos con el anagrama de la Virgen María alimentando a sus polluelos con la sangre que sale de sus llagas, todo ello acompañado de unos hermosos poemas referenciados a la Madre de Dios.

\section{Conclusiones}

El antiguo convento de la Magdalena en Antequera es un magnífico ejemplo del barroco andaluz, donde se aúnan unos valores artísticos, culturales y espirituales excepcionales. El hecho de poder aportar las fuentes literarias, nos ayuda a comprender el verdadero significado intrínseco del conjunto, destacando, en primer lugar, el libro del fundador de la Orden, san Pedro de Alcántara, Tratado de Oración y Meditación, donde propone un Itinerarium para conseguir la unión del alma con Dios. Este concepto básico es apoyado con la reproducción de 16 poemas, copiados del libro del místico franciscano alcantarino Antonio Panes, Escala Mística y estímulo de amor divino, aportando dos ideas básicas la justificación de la purgación de nuestros pecados, mediante la oración y la mortificación y la exaltación de la Virgen María como madre de Cristo e intercesora para conseguir el paraíso. La otra fuente literaria encontrada es el libro de de Juan Esteban de la Torre, La Pecadora santa. Vida de santa María Magdalena. Historia Panegírica, política y moral. que sirve de soporte a la idea de que todo hombre ha pecado o puede pecar en múltiples formas, pero gracias al arrepentimiento y penitencia puede conseguir el perdón y alcanzar el cielo, siendo María Magdalena la imitatio y el exemplum del hombre que quiere salvar su alma, por ello se representa en los muros perimetrales del claustro bajo doce escenas que relatan la vida de María Magdalena y que constituye una magnífico y excepcional 
sermón plástico. Estas escenas tienen su correspondencia, de una forma total o parcial, con los grabados del taller de la prestigiosa familia flamenca de los Sadeler.

Este espacio anacoreta nos traslada a un mundo místico y espiritual, donde las diversas artes, arquitectura, pintura y literatura se integran para un fin, conseguir la unión el alma con Dios, gracias a la vida ascética que tiene que seguir el monje alcantarino, mediante la oración, la mortificación, la penitencia, el arrepentimiento, el sufrimiento, el desaliento y el dolor conseguir el desapego sensitivo del cuerpo.

\section{Referencias bibliográficas}

ALCÁNTARA, Pedro de. (2012). Tratado de la Oración y Meditación. Ed. Biblioteca de autores cristianos: Madrid.

CAMACHO MARTÍNEZ, Rosario (1999), "Patrimonio pictórico de Antequera. El claustro del Convento de la Magdalena”, en Boletín de Arte no 20, Universidad de Málaga, pp. 471- 492.

CAMACHO MARTÍNEZ, Rosario (2008), "Del Desierto de penitencia al claustro conventual, pinturas murales y programas iconográficos del convento de la Magdalena en Antequera", en PAREJO, Antonio, (coord.). El Antiguo Convento de la Magdalena de Antequera: Historia y Patrimonio (1558-2008), Ed. Grupo Antequera golf: Antequera.

FERRER, Vicente. (1791). Tratado de la Vida espiritual del glorioso padre S. Vicente Ferrer, orden de predicadores traducido de latín a romance con las licencias necesarias..., Oficina de D. Benito Monfort: Valencia.

GONZÁLEZ DE ZARATE, Jesús María y VV. (1996), “Las estampas de los Sadeler como transmisoras de modelos iconográficos en la pintura flamenca del siglo XVII”, en Goya, n 251, pp. 265-275.

GREGORIO MAGNO. (2000). Homilías sobre los evangelios. Ed. Rialp,: Madrid.

LÁZARO PULIDO, Manuel (2006), “El acceso antropológico a la meditación con Dios en el Tratado de Oración y Meditación de San Pedro de Alcántara”, en Cauriensia, vol.I, pp. 237 250.

BARTSCH, Adam von (2003). The Illustrated Bartsch 70 part 4 (supplement) Johan Sadeler I. Ed. Abaris Books: Nueva York.

PAREJO BARRANCO, José Antonio (2002), “Una lectura simbólica de la Antequera Barroca (fragmentos)", en Revista de Estudios Antequeranos, nº 13, p. 14. 
PAREJO BARRANCO, José Antonio (2008), “Antequera y el antiguo convento de la Magdalena. Del siglo XVI al XXI: Dos historias paralelas” en PAREJO, José Antonio (coord.), El Antiguo Convento de la Magdalena de Antequera: Historia y Patrimonio (1558-2008), Ed. Grupo Antequera golf: Antequera.

RÁMIREZ GONZÁLEZ, Sergio (2007). Málaga seráfica. Arquitectura, patrimonio y discurso simbólico de los conventos franciscanos (1485-1835). Tesis Universidad de Málaga: Málaga. SÁNCHEZ LÓPEZ, Juan Antonio (1991), "Iconografía e Iconología del pelícano: Un ensayo sobre la reconversión del concepto de filantropía”, en Boletín de Arte, $\mathrm{n}^{\circ}$ 21, Universidad de Málaga.

ROMERO BENÍTEZ, Jesús (2012). Antequera Ciudad Monumental. Ed. Chapitel: Antequera. TORRE, Juan Esteban de la (1688), La Pecadora Santa. Vida de Santa María Magdalena. Historia Panegírica, Política, y Moral. Dedicada Al Antiquissimo, Nobilissimo, y fidelissimo Reyno de Aragón. En Calatayud, por Josef Mola.

VORÁGINE, Santiago de la (1982). La Leyenda Dorada, vol I., Ed. Alianza: Madrid.

VILLEGAS RUIZ, Manuel (2002), "El convento de la Magdalena de los franciscanos descalzos de Antequera, según una crónica latina del siglo XVIII”, en PELÁEZ DEL ROSAL, Manuel (dir.), V y VI Curso de Verano. El franciscanismo en Andalucía, Cajasur: Córdoba. 